a hundred in black and white photographs.

Together these two books provide valuable reference material on a global scale on two subjects that are usually fragmented.

JOHN CLEGG

\title{
From the Edge of Extinction: Endangered Species in North America, by Darryl Stewart. Warne, £6.95.
}

Mr Stewart takes 21 species of North American animals rescued from threats of extinction of varying severity. They range from the mighty bison, once 50 million strong, to the tiny Kirtland's warbler, never numerous, and from the now abundant beaver to the California condor, which may perhaps survive only by captive breeding. Each short chapter describes one species, gives a well-researched history of its tribulations and the legislative and other measures for its survival, and its present status and prospects. Every species is illustrated in black and white by the author, a former art student in London.

There is much in this book that is encouraging, particularly when one compares present dedicated conservation efforts with the previous indifference which cost the US (including Hawaii) 70 animals, most of them reaching final extinction in this century. Undoubtedly there has been a sudden upsurge in many countries of an awareness of the need for conservation, but not yet of a comparable awareness of how vast are the sums needed to pay for it. Both voluntary and government support for North American conservation compare most favourably with that to be found elsewhere, but even the US Fish and Wildlife Service (to which this book is gratefully dedicated) still lists 162 native species and subspecies as endangered. Yet funds to save habitats and species in Third World countries, with their desperate poverty and population problems, are much harder to raise, though it is there that they are most urgently needed if irreversible damage is to be kept within bounds in this century.

G.T. CORLEY SMITH

\section{East African Mammals: an Atlas of Evolution in Africa, Volume III Part B (Large Mammals), by Jonathan Kingdon. Academic Press, London, £55.}

Jonathan Kingdon is nearing the end of his road: this is the penultimate of the six tomes which will span the diversity of the mammal fauna of East Africa. With primates, small mammals and carnivores already behind him (in volumes I, IIA, IIB and IIIA) he tackles here the largest herbivores, reserving most of the even-toed ungulates for the final volume.

He tackles them in his usual way. He draws a profile of each family - elephants, rhinos, equids, pigs, hippos, camels, chevrotains, and giraffes - in which he considers the general themes of structure, evolution and way of life, with more emphasis on the fossil record than in previous volumes. He then takes each species in turn, and describes its distribution, ecology, coat pattern, behaviour, reproduction, and so on, all superbly illustrated as usual with his own drawings. These range from meticulous depictions of the whole animal, the skinned animal, and the skeleton, to the haziest of thumbnail sketches capturing the essence of a particular posture. They are as lively and informative as the text. My only major criticism of the book is that its bibliography is unnecessarily subdivided into three sections, making it both repetitious and maddening to use.

The book contains a fair number of maps, most of which convey the same gloomy message summarised in the Introduction: 'All the species described . . . are in a decline that has accelerated in recent years and can only continue.' The largest mammals are the most threatened because they generally need most land, reproduce relatively slowly, and are often unfortunate enough to carry valuable trophies in the form of tusks or horns. A huge amount of work has been involved in collecting the dismal statistics - for 
example that Kenya's elephant numbers in 1973 were 167,000 and only 4 years later 70,000 - but that is as nothing compared with solving the problem. The problem is people - too many wanting land for agriculture, ivory for ornaments, rhino horn for dagger handles, and too many everywhere wanting a share of the trade profits. Jonathan Kingdon's book does not tell us what we can do, but it will help both to alert us to the immense problems and to tell us about what we are in great danger of losing. One thing we can do is to visit East African wildlife areas and thereby help to boost wildlife. But you will probably be too late to see rhinos, or perhaps even elephants, in Uganda again, and even this book can scarcely compare with the real thing.

BRIAN BERTRAM

\section{The Wild Mammals of Malaya (Peninsula Malaysia) and Singapore, by Lord Medway. Oxford UP.}

Nine years after its first appearance this useful volume has been revised and produced in paperback. Lord Medway, now the Earl of Cranbrook, has also recently published the second edition of Mammals of Borneo (reviewed in the November 1978Oryx, p430), and for him to revise yet another volume is indeed praiseworthy, in view of the tedious nature of the task. Visitors to the Far East will be the main beneficaries.

The distribution, identification, habits, voice, life-history and subspecies of 206 species of the 32 families of 10 mammalian orders occurring in Malayia are described in 110 pages, with a further 18 pages of bibliography and index. Species are considered in terms of their known habitat types, altitudinal range and temporal or spatial separation, and whether they are (a) widespread in continental South and South-east Asia or (b) on the Sunda Shelf, or (c) endemic to the Malay Peninsula. Eleven line drawings and 15 excellent colour plates depict a wider range of species than is usual in such books. There is a concise and informative introduction, a useful glossary and keys to bats, rats and civets and mongooses.

This second edition differs from the first in the addition of 48 references, two new species and its cheaper price. Of more popular appeal than Mammals of Borneo, this book will be even more useful for visitors, whether tourists or scientists.

DAVID J. CHIVERS

\section{Population Dynamics: 20th Symposium of the British Ecological Society, edited by R.M. Anderson, B.D. Turner and L.R. Turner. Blackwell, $£ 20$.}

The dynamic changes that take place in plant and animal populations are the means whereby natural communities evolve. Man has recently (on the evolutionary time-scale) acquired the ability to accelerate or alter the direction of these changes very greatly. Sometimes we see these alterations as adversely affecting our interests, or those of the generations to come, and it is at this point that we may wish to step in to maintain the status quo, restore a desired system, or regulate exploitation. If follows that conservationists, or those appointed to manage the systems that we wish to control, must be familiar with the modern approach to the study of population dynamics. This book sets out to provide an up-to-date review of this rapidly expanding field. The contributors, who include many of the foremost names in the field, give an erudite and often challenging account of their recent work. Perhaps most of the papers in this book are directed to specialists rather than to the general scientific reader; certainly some knowledge of mathematical modelling is helpful in understanding many of the arguments put forward. Despite its title, this is not a book about population dynamics as such, but rather about certain topics and recent developments in the subject.

It is not easy to pick out a central theme. What comes through most clearly is the complexity of natural systems, or as R.M. May puts it: 'the richness of behaviour latent in the simplest of non-linear equations' (a quotation that gives the general flavour of the book). As we study natural systems we discover that the simpler models are inadequate; 